\title{
Welcome to the Visitors Center
}

\section{A Well-grounded Learning Experience}

The USGS Learning Program is designed to acquaint visitors with the USGS and its multi-faceted activities and responsibilities. Visitors to the Learning Center will be actively engaged in learning about natural science through guided tours, hands-on experiences, and a fascinating array of natural science products.

\section{Self-guided Tours}

Self-guided tours of the indoor and outdoor exhibits are available Monday through Friday from 9:00 a.m. to 4:00 p.m. During fair weather months, visitors may probe for ground water at a well, examine large rock specimens, and observe forest life.

\section{Customized Group Tours and Activities}

Whether you belong to a community group; professional society; elementary, middle, or secondary school class; or a family group, our USGS staff will create a tour with activities geared to your particular interests.

\section{Book Your Guided Tour in Advance}

To ensure that your visit to the USGS is as rewarding as possible, we request that guided tours be scheduled in advance. Please call to make an appointment. The Visitors Center is open from 8:00 a.m. to 4:00 p.m. Tours are approximately 2 hours long and are scheduled to run within the following times:

Mondays 1:00 p.m. - 4:00 p.m. Tuesdays 9:00 a.m. - 4:00 p.m. Thursdays 9:00 a.m. - 4:00 p.m.
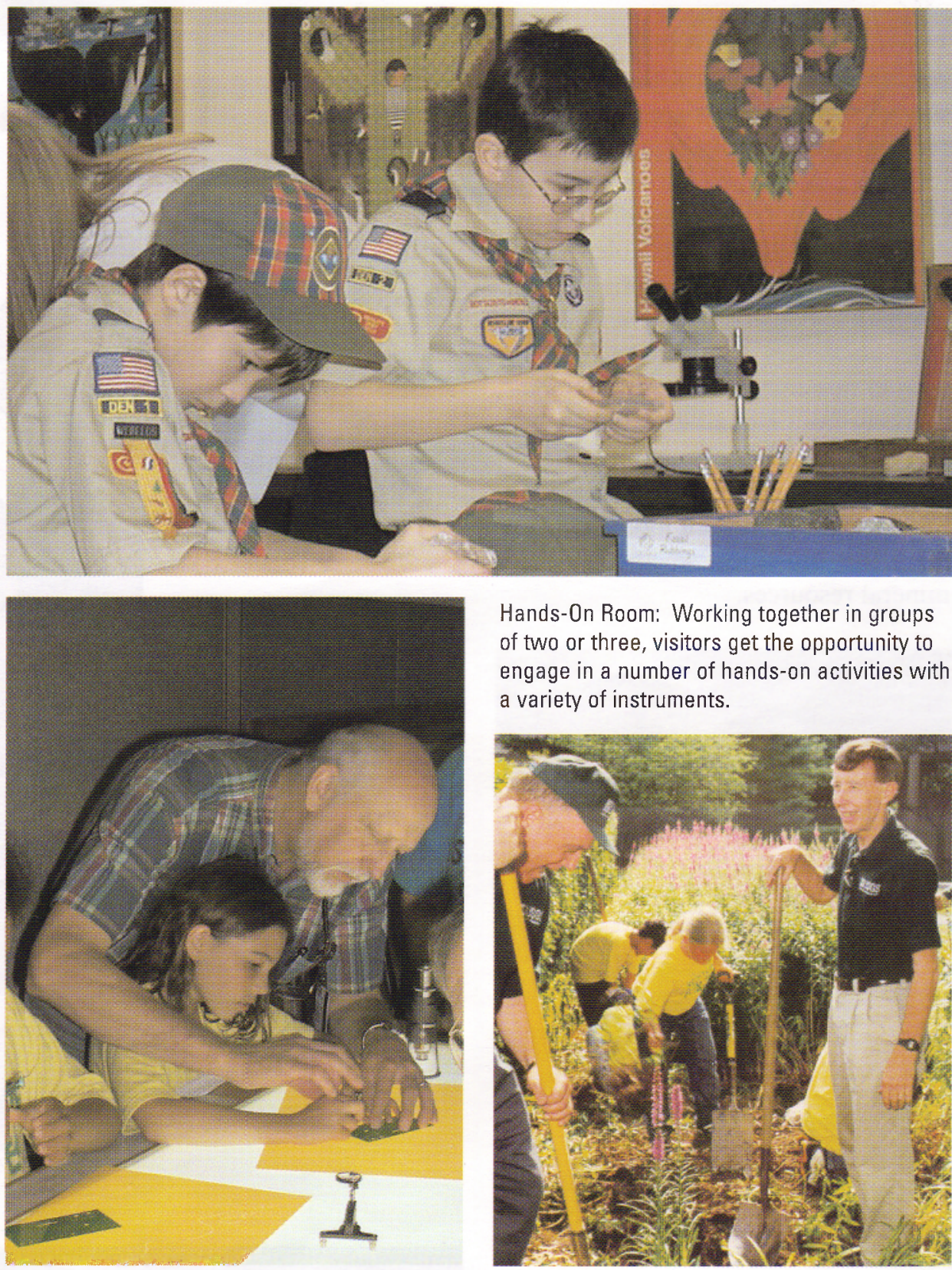

Hands-On Room: Working together in groups of two or three, visitors get the opportunity to engage in a number of hands-on activities with a variety of instruments.

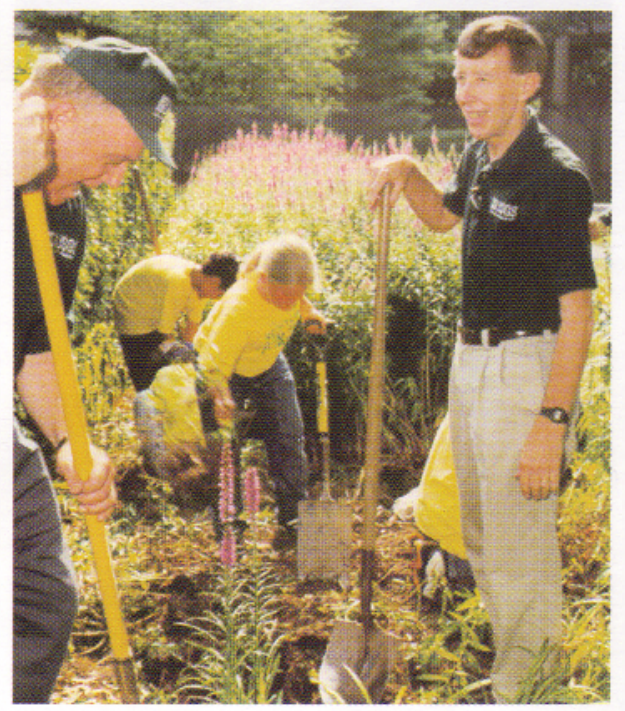

For more information or to schedule a tour call 64-VISIT (703-648-4748)
Visit the USGS Learning Center online! wพw.usgs.gov/visitors 


\section{Welcome to the USGS National Center}

The National Center is the headquarters of the USGS, which serves as the Nation's premier earth and biological science agency. The USGS works in cooperation with more than 2,000 organizations across the country to provide reliable, impartial scientific information to resource managers, planners, and other customers. This information is used to minimize the loss of life and property from natural disasters; safeguard the nation's natural resources and enhance the quality of life through the careful monitoring of our water, biological, energy, and mineral resources.

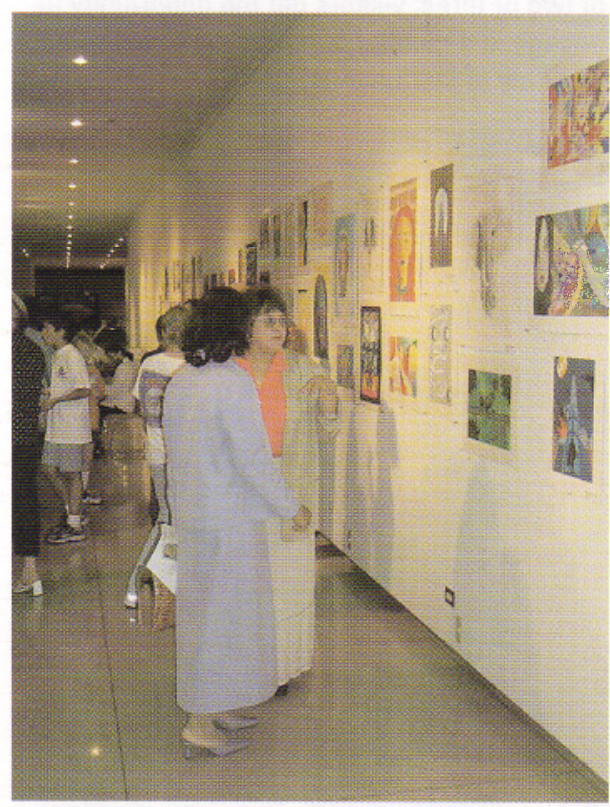

Art Exhibits: Each month, in the main hallway of the National Center, visitors can view a new art exhibit from schools, local artists and photographers, minority groups, and USGS employees.

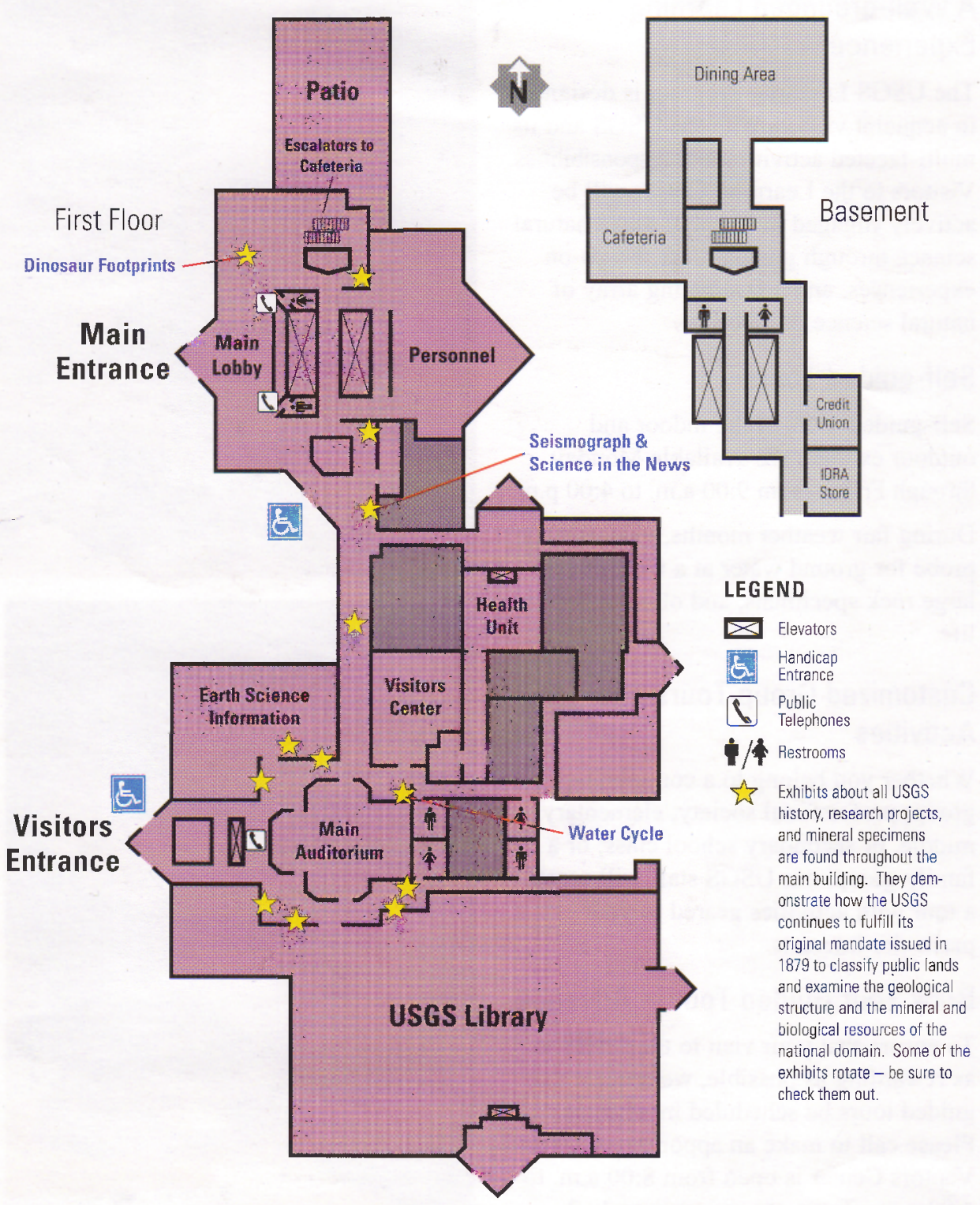

\section{For More Information}

Learn more about USGS at www.usgs.gov or call 1-888-ASK-USGS. 